
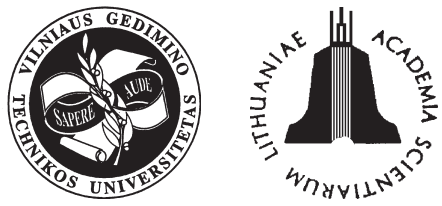

\title{
NEW STREET SCENE FOR PEDESTRIANS AND DRIVERS
}

\author{
Branimir Stanić, Smiljan Vukanovic, Miroslav Osoba \\ Faculty of Transport and Traffic Engineering, University in Belgrade, \\ Vojvode Stepe St. 305, 11000 Belgrade, Serbia and Montenegro, \\ E-mail:lorens@sf.bg.ac.yu
}

Received 30 June 2005; accepted 30 September 2005

\begin{abstract}
In the last twenty years all cities throughout the world have faced a continual increase in traffic demand. Neither a simple increase in physical capacities of the traffic network nor introduction of new traffic control systems nor similar isolated actions can be the right response to the increased traffic demands. New approaches to traffic management and application of complex new technological solutions in traffic control are called for. Besides improving safety for all participants, their main objectives are to increase the capacity of the existing infrastructure to enable its efficient exploitation in accordance with the current traffic demand and to protect urban environment from unnecessary traffic aggressive influence. It is clear that to achieve traffic flow the following issues should be taken into consideration: (1) Traffic conditions (to reduce duration and scope of traffic jams, to increase capacity and level of safety); (2) Physical surroundings (less noise and less pollution), and (3) Economic conditions (efficient usage of time, energy, space and other resources). Management of traffic means the possibility to choose an adequate management algorithm and the possibility to adapt it to the constant changes in traffic demand and not so dynamic changes in urban surrounding demand.
\end{abstract}

Keywords: pedestrians, street design, people with disabilities, solution evaluation.

\section{Introduction}

Belgrade, the city with ca 1600000 inhabitants, after years of modest or nearly without any investment into transportation system at all, has initiated activities (in last two years) rapidly to overcome these shortcomings. Conflicts between various strategies are very much present, and sometimes, at a given moment, difficult to overcome. In 2001 and at the beginning of 2002, city authorities, after detailed analysis, decided maximally to adapt one of the main streets in the city centre, King Milana Street, to became more suitable for pedestrian traffic (as representation of general urban conditions improvement). Entire reconstruction was finished in six months. After opening this street for traffic, considerable positive indicators have been recognized, such as increased level of pedestrian flow services, smaller level of pollution (elimination of buses from the street, only trolleybuses are in use), less accidents, etc [1-5].

The procedure of finding an acceptable solution for pedestrianization and a design of a new street scene is presented in this paper with the emphasis on the following segments:

- Objectives of reconstruction of King Milana Street (KMSt),
- Strategies in consideration - Possible conflicts,

- Traffic indicators before alteration of traffic in KMSt,

- Generation and analysis of possible options of traffic in the wider area and in KMSt,

- Solutions carried out,

- Effects of newly introduced solutions for KMSt and a wider area, and

- UTC of the central area of Belgrade and pedestrianization of KMSt.

A view of a part of the central zone of Belgrade is presented in Fig 1. KMSt occupies the central part in this Figure and it shows that the central area of the city is fully developed with already formed urban structure.

The basic objectives of traffic management algorithms such as safety level, capacity, travel time etc., can easily be defined, but it is not always simple to define their values under local conditions [1-5].

Changes of the scope and character of traffic demand in towns and cities create the need of constant re-examination and modification of the current management strategies, as well as the adjustment of objectives in order to prevent possible unfavorable traffic situations. In addition, certain strategies have 
a larger impact on one traffic condition than on the other. A conflict between strategies is common and requires adoption of a hierarchy of individual strategies in time and space [1-5].

KMSt is one of the oldest streets in the city of Belgrade. Since urban context of this street was formed in the nineteenth century its reconstruction was carried out under conditions of great construction limitations, i.e. with minimal possibilities to widen the streets and intersections. Adequate planimetry of the central zone of the city is presented in Fig 2.

\section{Generation and analysis of traffic options in a wider area and in KMSt}

General improvement of street scene and environment conditions for pedestrians and other users

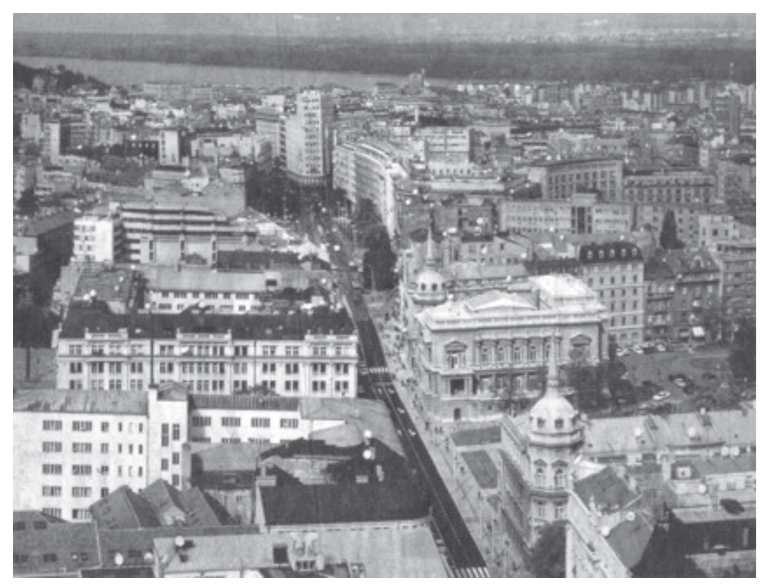

Fig 1. Central zone of Belgrade was started from the reorganization and redesign of the space directly and indirectly dedicated to pedestrians: pavements, pedestrian crossings and supporting facilities, reorganization in carriageway profile use, traffic management schemes etc.

In the scope of pavements specially marked paths-lanes were made for the blind and visually impaired pedestrians. These paths-lanes are made of specially designed road surface material: warning areas (change of movement direction, approaching carriageway curb or a structure) are marked by point texture; while line texture is intended for movements "from point to point", i.e. from one intersection to another intersection. The detection of such information is performed with the help of white sticks (for the blind). At the figures the path-lanes are highlighted (pictures edited) with white frames for easy recognition of lanes layout.

The basic objective of these markings is their simple logic and comprehension with no need for any additional equipment, as well as the fact that they are universal.

Fig 3 shows a basic view of such a path-lane that is positioned in the centre of the pavement and a view of an "intersection" on such communication with the change of movement direction. A white frame is edited on the picture(s) to stress different surface structures (fields).

These markings are applied with the idea to promote protection of and care for the people with disabilities, because in the previously built urban structures relatively little attention is devoted to their needs.

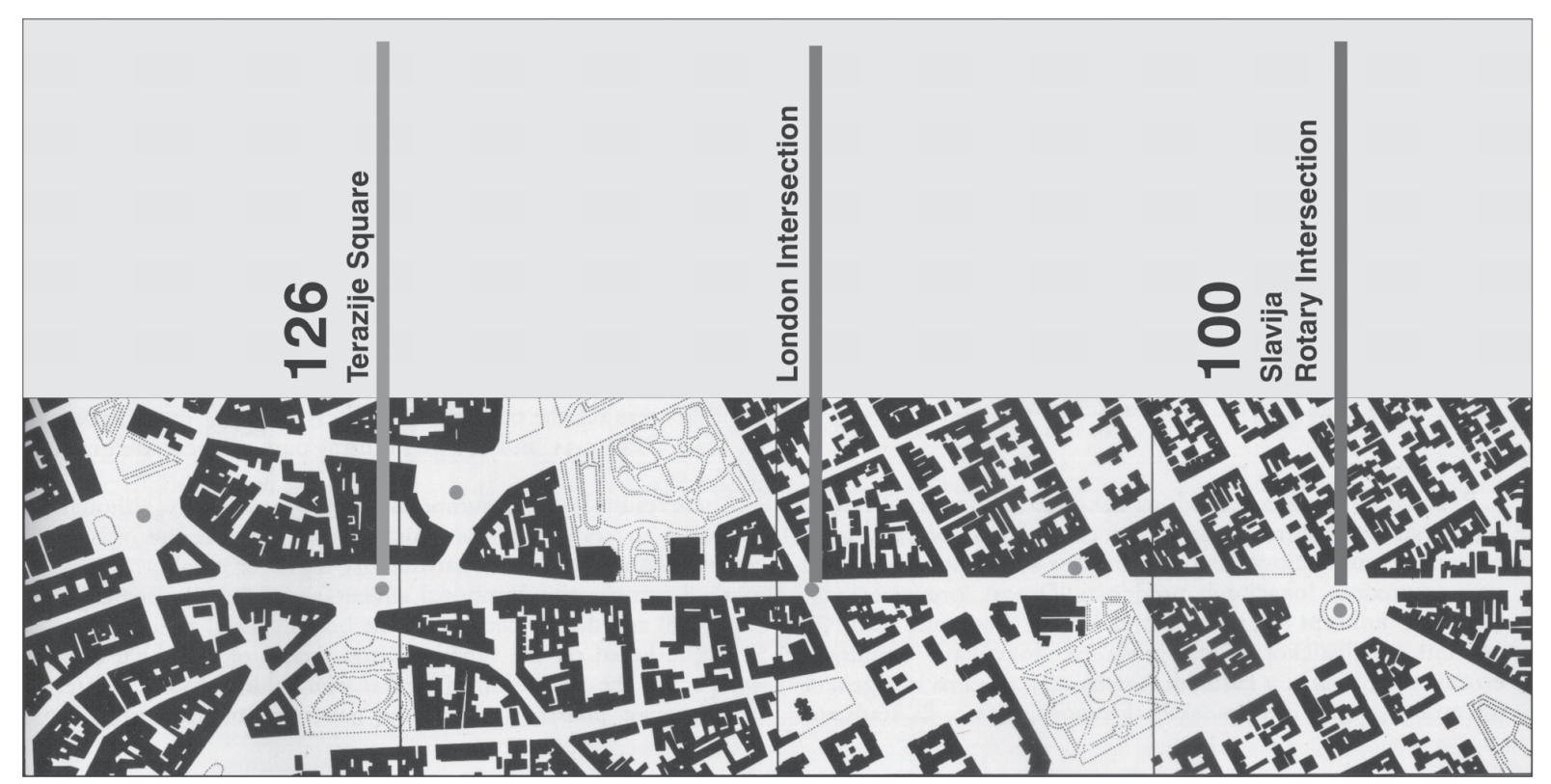

Fig 2. A dequate planimetry of the central zone of the city 


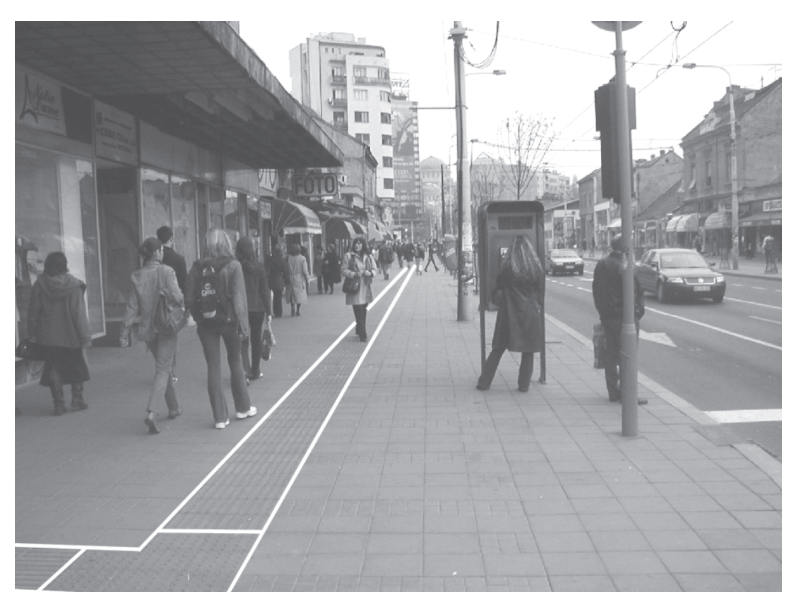

Fig 3. Basic view of such a path-line

Personal assistance to the blind and visually impaired pedestrians, particularly assistance to get on the vehicles in public transportation, is one of the main problems to be faced by people with disabilities as well as by designers. Standard bus stop facilities usually are not adapted to meet such requirements. Fig 4 shows personal assistant assisting the blind and visually impaired pedestrians to get on a bus at a bus stop. The curbs along the street are of higher type to prevent vehicle climbing and parking on the pavement, that, in addition to special low-floor buses, makes disabled people approach to public transport vehicles easier.

A pedestrian ramp connecting a pavement with a carriageway was made at every spot at the intersection with pedestrian crossing. These ramps have markings for the blind and visually impaired as well - Fig 5. The different texture indicates the zone of higher risk and more care needed.

These ramps are also intended for easier movement of mothers with prams as well as for the wheelchair users.

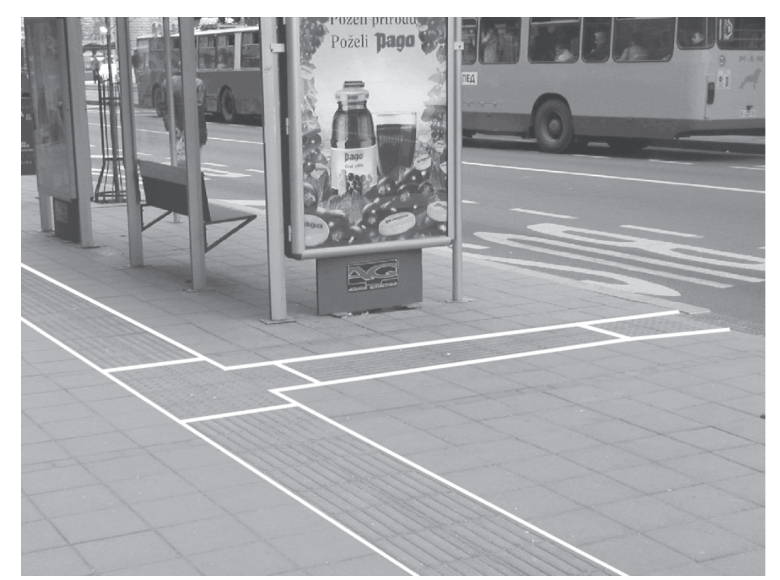

Fig 4. Standard bus stop

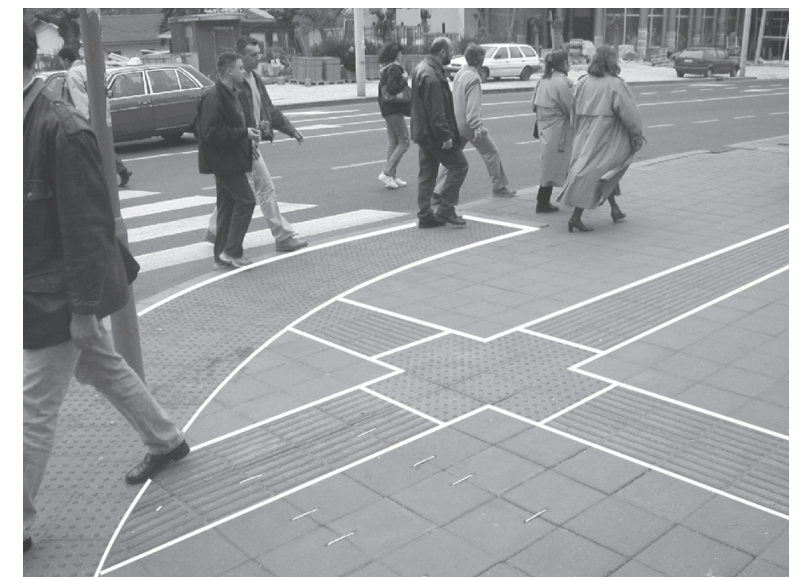

Fig 5. Pedestrian ramps

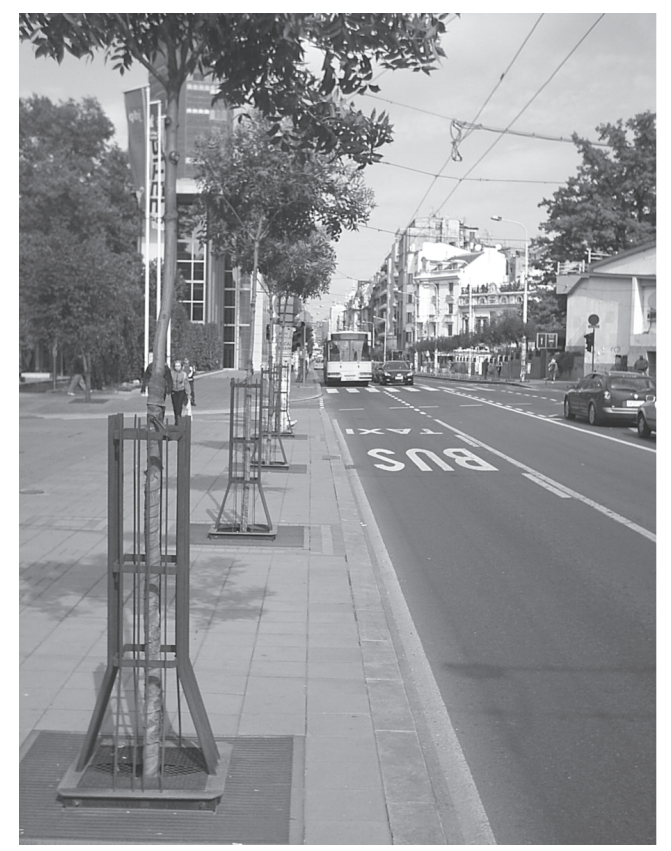

Fig 6. Protection of the line of trees

Therefore, usual position of light signals in Belgrade (middle of pedestrian crossing) had to be changed. They are moved to the side. Special noise signals for the blind on the light signal posts should enable blind and visually impaired people to have relatively safe communication during movements at the pedestrian crossings at which a conflict with motorized traffic is present.

After removing all structures from the pavement, pavement front remained free from obstacles that could hamper assistance to the visually impaired.

The increase of the space available for pedestrians by itself creates better impression on the regulation of the street. In this way the number of street movement conflicts is reduced, and, at the same time, the level of pedestrian movement service is increased.

The movement between obstacles on one side 
and shop windows and structures on the other side looks more like wandering or roaming, say, a market, or a shopping mall.

Street scene with its new design is reduced to the most essential contents, allowing pedestrians' attention to be focused more on the ambient and its values than on the ongoing street trade.

There is only the most essential street equipment, and particular attention is devoted to the protection of the lines of trees (Fig 6).

In addition to the described solutions, it should be mentioned that new street lighting and illumination of some significant structures are planned.

\section{Traffic indicators before and after alteration of traf- fic in KMSt}

\subsection{Objective state}

The reconstruction of KMSt, i.e. temporary suspension of traffic of all motor vehicles during construction work influenced alterations in spatial traffic distribution, primarily at intersections in the area in the vicinity of the street under reconstruction, but also in some more distant city areas from which drivers start their movements towards the city centre.

Table 1 shows the ratio of entrance flow into a wider zone around the area under reconstruction. Alterations relating to the state "before" (year 2001) and "after" (year 2002) were quantified by their com-
Table 1. Traffic volume (veh/hour) 8 to 9 h. a. m.

\begin{tabular}{|c|c|c|}
\hline Location-station: & Year 2002 & $2002 / 2001$ \\
\hline 050 - from New Belgrade & 2114 & 1,08 \\
\hline $\begin{array}{l}126 \text { - from Kolarceva } \\
\text { Street }\end{array}$ & 818 & 0,97 \\
\hline $\begin{array}{l}072 \text { - from the Youth } \\
\text { Centre }\end{array}$ & 728 & 0,78 \\
\hline 107 - from TV Building & 1375 & 0,96 \\
\hline $\begin{array}{l}106 \text { - from Tašmajdan } \\
\text { Park }\end{array}$ & 976 & 1,09 \\
\hline $\begin{array}{l}268 \text { - from Sarajevska } \\
\text { Street }\end{array}$ & 1244 & 2,40 \\
\hline 100 - Slavija Roundabout & 3345 & 0,64 \\
\hline
\end{tabular}

parison with flow rates in 2001. It can be seen that visible alterations were registered first of all in Sarajevska Street (2.4 times increase) and in Slavija Rotary Intersection (reduction by $46 \%$ ). Other alterations do not exceed the limit of $+/-10 \%$, what can be considered random alteration of traffic load.

If alterations are observed in relation towards King Aleksandar Boulevard and Nemanjina Street, the following can be noticed (Table 2, Fig 7):

- Entrance into the city through this corridor decreased by $16 \%$;

- Movement from the central area of the city was reduced by $9 \%$ related to the year 2001;

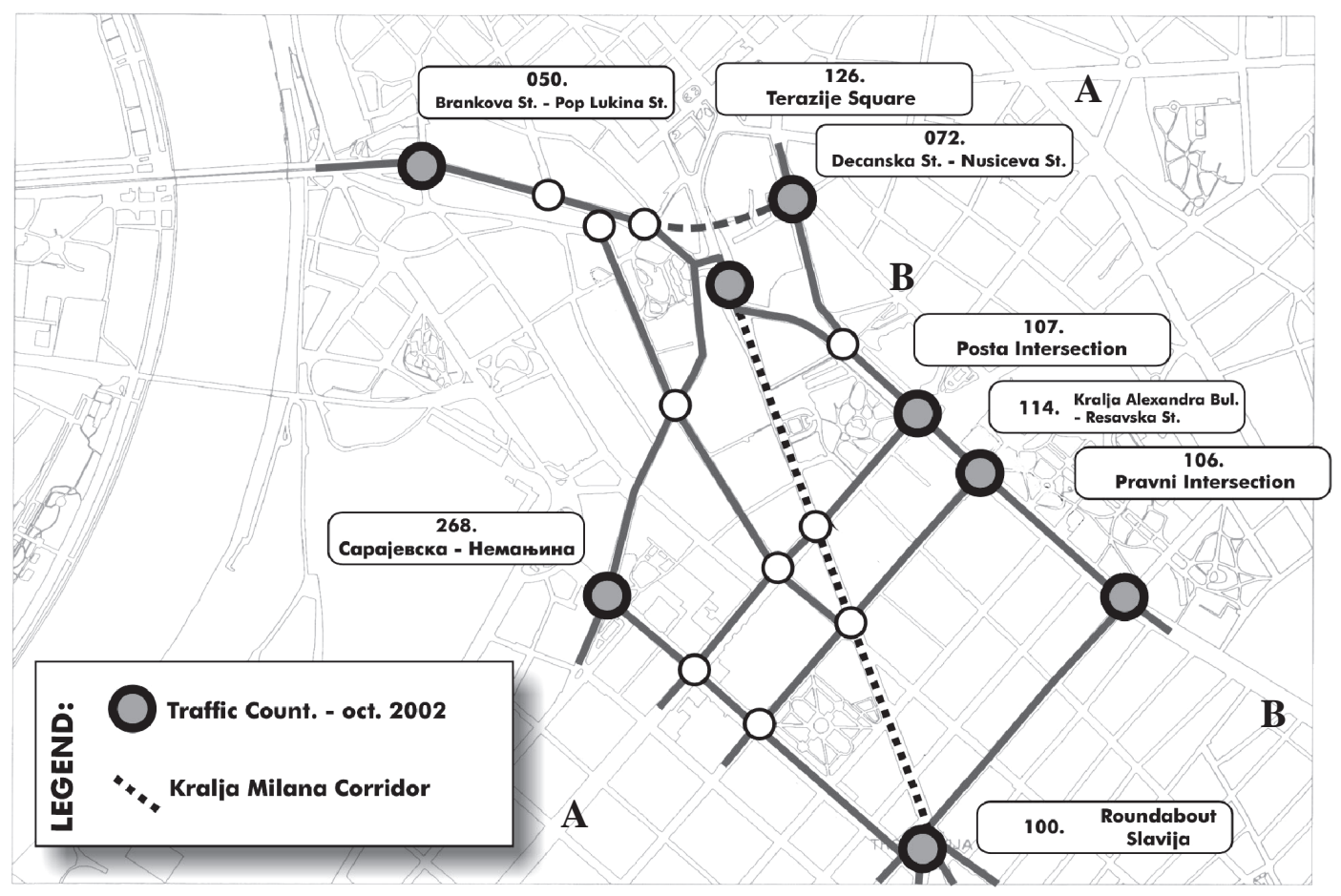

Fig 7. KMSt with refferent street network 
Table 2. Traffic Volume (veh/hour) 8 to 9 h. a. m.

\begin{tabular}{|c|c|c|c|}
\hline Location-station: & Year 2002 & Year 2001 & factor \\
\hline 107 - from centre & 1023 & 1122 & 0,91 \\
\hline 107 - towards centre & 1209 & 1434 & 0,84 \\
\hline
\end{tabular}

- Functioning of the intersection in front of the Faculty of Law was disturbed by buses turning into and from Beogradska Street (to the left from Beogradska Street into King Aleksandar Boulevard 62 vehicles), i.e. from King Aleksandar Boulevard into Beogradska Street (82 vehicles registered); it is obvious that these vehicles were not there during traffic counts in 2001.

Practically the greatest change in traffic volume was registered in Nemanjina Street (among observed intersections), and it was in the direction from Railway Station towards Slavija Rotary Intersection (this direction in a way represents one of movement alternatives for KMSt) (Table 3):

At Slavija Rotary Intersection the following can be observed (Table 4):

- Total number of vehicles entering Slavija Rotary Intersection is reduced in 2002 by approximately $23 \%$ related to 2001 . These data can support the statement that due to the reconstruction of KMSt there occurred considerable and intensive redistribution in vehicle traffic in a wider area around the city centre,

- "City entrance" from JA Boulevard corridor is approximately the same (this corridor has been operating for a long time practically with its full capacity), etc.

If we compare traffic counts carried out in the period of 8 to 9 hours with the traffic counts carried out in the period of 11 to 12 hours (on the same day in 2002) it can be noticed that there are no significant differences in the results obtained.

Table 3. Traffic volume (veh/hour) 8 to 9 h. a. m.

\begin{tabular}{|c|c|c|c|}
\hline Location-station: & Year 2002 & Year 2001 & factor \\
\hline 268 - from centre & 777 & 378 & 2,05 \\
\hline 268 - towards centre & 579 & 633 & 0,91 \\
\hline
\end{tabular}

Table 4. Traffic volume (veh/hour) Slavija Roundabout, 8 to 9 h. a.m.

\begin{tabular}{|c|c|c|c|}
\hline Location - station: & $\begin{array}{c}\text { Year } \\
2002\end{array}$ & $\begin{array}{c}\text { Year } \\
2001\end{array}$ & Factor \\
\hline 100 - from Makenzijeva St. & 584 & 721 & 0,81 \\
\hline 100 - from JA Boulevard & 1331 & 1400 & 0,95 \\
\hline 100 - from Nemanjina St. & 824 & 1421 & 0,58 \\
\hline 100 - from Beogradska St. & 606 & 793 & 0,76 \\
\hline
\end{tabular}

It can be seen that these differences do not exceed limit $(+)$ or $(-) 10 \%$, what, as already mentioned before, can be considered random change of the traffic load (Table 5).

Table 5. Traffic volume (veh/hour) in 2002 year

\begin{tabular}{|c|c|c|c|}
\hline Location - .station: & $\begin{array}{c}8-9 \\
\text { hours }\end{array}$ & $\begin{array}{c}11-12 \\
\text { hours }\end{array}$ & $\begin{array}{c}\text { factor } \\
9 / 12\end{array}$ \\
\hline 050 - from N Belgrade & 2114 & 2172 & 0,97 \\
\hline 126 - from Kolarceva St & 818 & 767 & 1,07 \\
\hline 072 - from Youth Centre & 728 & 829 & 0,89 \\
\hline 107 - from Takovska St & 1375 & 1330 & 1,03 \\
\hline 106 - from Tašmajdan & 976 & 915 & 1,06 \\
\hline 268 - from Sarajevska St & 1244 & 975 & 1,30 \\
\hline
\end{tabular}

There is another characteristic change on the approach from Youth Centre in Dečanska Street, where an increase of $11 \%$ in traffic load related to the morning period was registered.

\subsection{Other urban analyses and traffic simulation}

Undoubtedly traffic represents one of the most significant, and in the scope of entire solution one of the most influential factors of the reconstructed street, and therefore special attention was devoted to the upgrading of traffic. Urban context with already built structures, profiled sidewalks and side streets, formed intersections and focus points determined long ago does not allow for a large manoeuvring space for interventions. Due to these reasons the most significant objective of the task undertaken was to increase the efficiency of traffic along the reconstructed corridor, to provide necessary accessibility to adjacent referential spaces and to minimize undesirable ecological effects of traffic in the surrounding area (safety and comfort of non-motorized movement, noise and air quality).

In other words, urban context was upgraded by applying indirect measures without the relocation of activities from the specified area and without limitations associated with previous use of this area.

In order to have a qualitative traffic solution which will, owing to its quality, support and justify the entire reconstruction of this section, the selection of the most suitable among alternative traffic solutions was made with the utmost care. Computer traffic simulation was used as a tool for qualitative and objective evaluation of hypothetical traffic solutions in the specified urban context.

In this particular case traffic simulation was made applying VISSIM Programme and optimization of traffic signals management was made applying its subprogramme - CROSSIG (authors of both 
programmes are experts of German PTV from Karlsruhe).

Several important issues related to traffic have been opened:

- $\quad$ reservation of this section exclusively for mass transport or putting it at disposal of individual users as well;

- restriction of mass transport exclusively to trolleybus transport or to allow this section to be used for servicing bus lines as well;

- reduction of traffic capacity at this section by consistent use of lanes reserved for mass transport or to allow more liberal use of these lanes by individual users as well;

- $\quad$ keeping or abolishion of public transport stop located approximately in the central part of this section;

- optimization of operation of traffic lights along this section according to the requirements of public transport or individual users.

The traffic solution which was delicate for the public was the decision consistently to mark and "defend" (put into operation with strong police enforcement) the lanes reserved for public transportation vehicles along this entire section.

Previous liberal traffic regime was more tolerant in this aspect and it implied that yellow lanes should be used when regarded more convenient option, but at the same time taking care that the interference with the movement of public transport vehicles is as minimal as possible.

It is clear that the capacity of the section intended for other users is considerably reduced (single lane per each direction) by strict reservation of lanes for public transportation exclusively. Consequently it was expected that conditions in serving individual motorized flows would become worse, and that the initiation of certain redistribution of the flows on alternative traffic network would follow, as well as the modification of traffic picture in the observed section. The reconstruction of the expected traffic picture was assisted by real change in movement matrix on referential traffic network which was registered in the period of construction work and reduced traffic in this section.

Irrespective of evidently favourable results obtained from the measures undertaken (both by measurements and simulation), city authorities are still somewhat reserved to the idea of preserving KMSt as an important city communication. Occasional actions of closing this street and transforming it into a pedestrian-and-cyclist-street only (one weekend a month), as well as favourable response to such actions by citizens, confirm the argument that this street, despite of its high traffic significance, can from time to time be closed for motorized traffic. The obvious question remains: is nearby street network capable of accommodating such modifications and is such a change in urban context reasonable in the city centre deficient of street network?

Another crucial traffic issue requesting the solution was the location of the bus stop. One of the possibilities of organizing traffic in KMSt was the option to reserve this street exclusively for mass transport users, i.e. totally to prohibit individual motorized traffic. Along similar streets and corridors typically (almost traditionally) bus (trolleybus) stops are positioned at street ends and somewhere around central parts of the streets (Fig 8). In the case of KMSt this

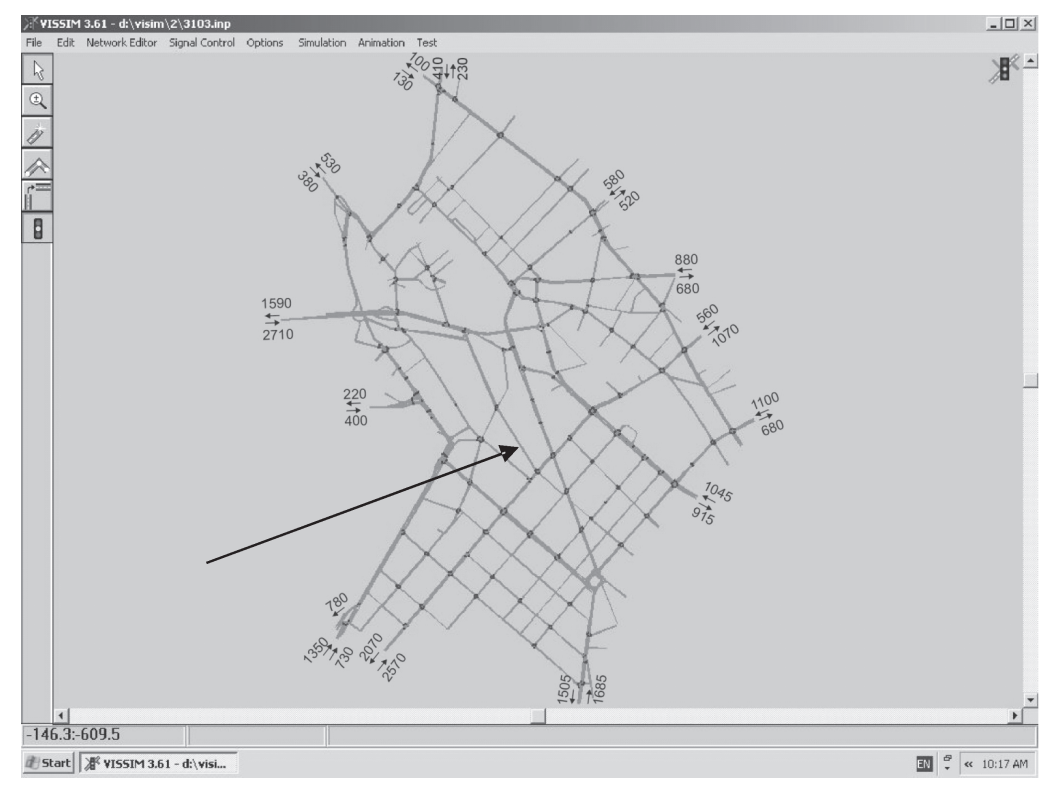

Fig 8. Simulated wider street network refferent for KMSt corridor 
concept is in compliance with the concentration of public contents present along this section. On the other hand, associate users' routine to access certain locations has been developed as well. These stops are located on the carriageway since there are no spatial possibilities to relocate them in specially designed spaces. Possible extension of the carriageway and separation of stops on account of the carriageway would considerably reduce the quality of the area dedicated to pedestrians in the street scene and it would affect discontinuity of pedestrian collimation line along the street as well as perception of far points of reference in the street (at one end Slavija Rotary Intersection and on the opposite end Albanija Palace - see Fig 1 and Planimetry Plan - Fig 2).

From the point of view of traffic management the location of the stop in the central part of the section makes traffic situation more complicated causing disharmony in the movement of public transport vehicles and other motorized flows. Regarding coordination of traffic light operation which is absolutely necessary along this section, dilemma is which of these two user groups is to be better supported by coordination.

Alternative traffic regimes were reconstructed applying a computer traffic model of this section and alternative management solutions (traffic lights operation regimes along this section) were applied to these traffic regimes. Traffic arguments with which phase of assessment and selection of the final traffic proposal for the solution of KMSt section were entered were provided to the designer by the simulation results. Although not all decisions were based on the simulation results more objective insight into "price" of their selection could be obtained, i.e. decisions were made in such an ambient in which the consequences of each action to be undertaken could be foreseen. For example, the abolishion of bus stop in the central part of this section creates preconditions for considerably more efficient management of motorized traffic, but accessibility to numerous contents is put at risk, so that this option was abandoned. This represents a very important example of "linking" the use of an area in a specified urban context with the potentials of traffic operation. Naturally, the present use of the space under consideration is in a way fixed/defined and it is not possible to relocate it or to make compensation with some other contents.

Certainly, the intent to attract potential users and pedestrians into the area under consideration (with the aid of mass transport) would surely create certain problems related to traffic management and, without doubt, it would reduce the efficiency of this street (if under efficient street we consider a street in which traffic flow is carried out with little interference and interruption).
The solution based exclusively on trolleybus public transportation unquestionably has its advantage from the environmental point of view. However, the accessibility of such parts of the street network to the users is jeopardized by this solution because a trolleybus line network does not cover all referential (remote) city areas as conveniently as a bus transport network. In order to compensate this disadvantage it would be necessary to provide the transfer of users from bus to trolleybus transport in the zone of Slavija Rotary Intersection. Even without this transfer Slavija Rotary Intersection has extremely saturated and congested traffic so that such transfer would additionally reduce the comfort and efficiency of transit ride of users. Due to these reasons this proposal has been abandoned for the time being.

By way of computer simulation alternative operation regimes of traffic lights were considered for the option of exclusive yellow lanes, stops in the central part of the section and coordination of traffic light operation optimized in accordance with the movement of individual motorized users.

\section{Effects of newly introduced solutions to KMSt and to the wider area}

The analysis of traffic counts "before" and "after" reconstruction of KMSt shows that traffic flow in 2002 was lower than traffic flow in 2001 (Table 6).

It can be concluded that direction A (exit from corridor towards Slavija Rotary Intersection) is lower by $5 \%$, i.e. entrance into corridor (towards city centre) is decreased by $10 \%$. If we apply previous interpretations, these occurrences can be considered random occurrences as well. If total number of vehicles is observed for London Intersection, then we can say that a decrease below $13 \%$, related to 2001, was registered. London Intersection is good representation of the observed corridor because this is one of the busiest intersections on the street network in the central area of Belgrade.

The decrease of traffic flow is partially caused by the reduced number of buses owned by private transport providers.

The number of these buses in the new traffic regime is reduced by 45 vehicles, what, in the traffic flow regime was registered as decrease of 80 to $100 \mathrm{ve}$ hicles.

Table 6. Traffic in KMSt 7-20 hours

\begin{tabular}{|c|c|c|c|c|}
\cline { 2 - 5 } \multicolumn{1}{c|}{} & \multicolumn{2}{c|}{ Year 2001 } & \multicolumn{2}{c|}{ Year 2002} \\
\cline { 2 - 5 } \multicolumn{1}{c|}{} & veh. & PCU & veh. & PCU \\
\hline a. Terazije - Slavija & 10239 & 10616 & 9801 & 10057 \\
\hline b. Slavija - Terazije & 9999 & 10398 & 9060 & 9381 \\
\hline
\end{tabular}


The significance of this change is evident also from the obvious change in behaviour of drivers of the official city transportation company. In the previous traffic regime "private" and "public" buses used to overtake each other or to form lines of buses - what resulted in mutual disruption of operation.

Movement of public transportation vehicles with fewer disturbances in traffic flow provided better travel time (TT) (Table 7).

From the results obtained the following conclusions can be made:

- In the morning periods new regime provides better results in Terazije Street in the exit direction, and

- In the afternoon periods in Terazije Street the state is approximately the same, while in Vasina Street operating speed is increased by $7 \%$.

Prior to initiating reconstruction of KMSt, pedestrian count was carried out in the period from 8.00 a.m. to 4.00 p. m. on a working day at all pedestrian crossings and several street points. Traffic counts were carried out in June, what resulted in a considerably lower number of pedestrians due to summer season. It is estimated that during autumn the number of pedestrians may be increased by as much as $100 \%$.

Pedestrian counts show that the number of pedestrians increases in the vicinity of the inner city from slightly more than 6000 pedestrians at the pedestrian crossing near Slavija Rotary Intersection up to almost 35000 pedestrians in the area of Sremska Street - the entrance into the pedestrian zone. The most congested pedestrian crossing is the pedestrian crossing at Republic Square with almost 15,000 pedestrians in the observed period. A considerable number of pedestrians is registered at already mentioned London Intersection and, in the observed period it amounts to more than 10000 pedestrians, while at the intersection near Moscow Hotel this number amounts to ca 12000 pedestrians.
Control traffic counts carried out during autumn in 2003 show that the observed trends related to traffic flow remained unchanged:

Somewhat higher PCU value for the year 2002 (related to 2001) is caused also by the alteration in the structure within bus and trolleybus categories because a part of the fleet has been replaced with so called articulated vehicles, which, of course, have higher PCU equivalent compared with ordinary single buses.

\section{Conclusion}

In a wider urban area dominated by KMSt there is one significant transversal corridor (Fig $7 \mathrm{~A}-\mathrm{A}$ ) and one very long longitudinal (Fig 7 B-B). All three parts of the street network belong to the fixed connections in the city matrix. All three parts of the street network serve distance and local movements, so it is natural that they are ranked as city arteries.

Possible interventions are significantly limited by the position of these arteries, especially due to the fact that there are considerable pedestrian flows on them. All three mentioned parts of the street network, as well as the rhythm of the intersections, traffic profile and regime, are adapted to the movement of the vehicles. On the other hand, the design of the street is primarily aimed at better comfort of pedestrians and their segregation from motorized flows, applying street fortification. Due to these reasons the applied reconstruction is based on the maintenance of the inherited urban functions, but also on the intensification of attractions of the space designed for the pedestrians.

Pedestrian communications are accentuated by pavement finishing, lines of trees, as well as by lighting and urban furniture, so that it can be said that there exists reasonable segregation of pedestrians from motor vehicles in the street scene.

Table 7. Travel time (TT) "before-after", public transport, working day

\begin{tabular}{|c|c|c|c|c|c|c|}
\hline & \multicolumn{4}{|c|}{ Entrance into city centre } & \multicolumn{2}{|c|}{ Exit from city centre } \\
\hline & \multicolumn{2}{|c|}{$\begin{array}{l}\text { Republic Square-Students } \\
\text { Square }\end{array}$} & \multicolumn{2}{|c|}{$\begin{array}{c}\text { Terazije Street - Republic } \\
\text { Square }\end{array}$} & \multicolumn{2}{|c|}{$\begin{array}{c}\text { Students Square - Terazije } \\
\text { Street }\end{array}$} \\
\hline & \multicolumn{2}{|c|}{$\mathrm{L}=263$} & \multicolumn{2}{|c|}{$\mathrm{L}=466 \mathrm{~m}$} & \multicolumn{2}{|c|}{$\mathrm{L}=910 \mathrm{~m}$} \\
\hline & TT s. & $\mathrm{V}_{\mathrm{e}} \mathrm{km} / \mathrm{h}$ & TT s. & $\mathrm{V}_{\mathrm{e}} \mathrm{km} / \mathrm{h}$ & TT s. & $\mathrm{V}_{\mathrm{e}} \mathrm{km} / \mathrm{h}$ \\
\hline \multirow{2}{*}{$\begin{array}{c}2001 \\
\text { old state }\end{array}$} & 55 & 17 & 124 & 14 & 240 & 14 \\
\hline & 69 & 14 & 133 & 13 & 276 & 12 \\
\hline \multirow{2}{*}{$\begin{array}{c}2002 \\
\text { new state }\end{array}$} & 70 & 13 & 115 & 15 & 211 & 16 \\
\hline & 62 & 15 & 132 & 13 & 257 & 13 \\
\hline morning $2002 / 01$ & $+40 \%$ & $-23 \%$ & $-8 \%$ & $+7 \%$ & $-12 \%$ & $+15 \%$ \\
\hline afternoon $2002 / 01$ & $+11 \%$ & $+7 \%$ & $+1 \%$ & 1 & $-7 \%$ & $+8 \%$ \\
\hline
\end{tabular}


Table 8. Traffic volume in KMSt, 7-20 hours

\begin{tabular}{|c|c|c|c|c|c|c|}
\hline & \multicolumn{2}{|c|}{ Year 2001 } & \multicolumn{2}{c|}{ Year 2002 } & Year 2003 \\
\cline { 2 - 7 } & vehicles & PCU & vehicles & PCU & vehicles & PCU \\
\hline $\begin{array}{c}\text { a. Terazije Street - Slavija } \\
\text { Rotary Intersection }\end{array}$ & 10239 & 9801 & 10057 & 10616 & 9762 & 10041 \\
\cline { 1 - 7 } $\begin{array}{c}\text { b. Slavija Rotary Intersection } \\
\text {-Terazije Street }\end{array}$ & 9999 & 9060 & 9381 & 10398 & 9470 & 9842 \\
\hline factor (2001 base) & 1,0 & 1,0 & $\mathbf{0 , 9 8}$ & $\mathbf{1 , 0 8}$ & $\mathbf{0 , 9 5}$ & $\mathbf{1 , 0 2}$ \\
\hline factor (2001 base) & 1,0 & 1,0 & $\mathbf{0 , 9 4}$ & $\mathbf{1 , 1 4}$ & $\mathbf{0 , 9 5}$ & $\mathbf{1 , 0 9}$ \\
\hline factor (2002 base) & & & 1,0 & 1,0 & $\mathbf{0 , 9 7}$ & $\mathbf{0 , 9 5}$ \\
\hline factor (2002 base) & & 1,0 & 1,0 & $\mathbf{1 , 0 0 9}$ & $\mathbf{0 , 9 5}$ \\
\hline
\end{tabular}

Each intervention in urban space can be analysed from a number of different perspectives. This paper illustrates that joint efforts of city authorities, city planners and those engaged in traffic management provide better results for city users compared to sporadic actions to "trim" the city area. At that, the street scene is turned into a complex structure modified to multifunctional and heterogeneous requirements of numerous interested parties. Modern tools in such a context enable significant upgrading of assessment and argumentation in implementing certain ideas related to planning of the urban city context.

\section{References}

1. Vukanovic, S.; Stanic, B.; Rubinjoni, Z. Street management - The Pedestrianization of a Main Street in the Central Area of Belgrade. In: ETC - European Transport Conference, 8-10 October, Strasbourg, France, 2003.

2. Vukanovic, S. et al. City Network of Belgrade - Book of Traffic Counting (Истраживање карактеристика саобраћаја на подручју Града Београда), Transport and Traffic Engineerung Faculty, Belgrade, Transport and Traffic Engineerung Faculty,1986-2003 (in Serbian).

3. Stanic, B. et al. King Milan Street Corridor Project (Идејно решење коридора Улице краља Милана), Juginus, Belgrade, 2002 (in Serbian).

4. Stanic, B. et al: King Milan Street Zone - Book of Travel Time Characteristics (Време путовања у зони Улице краља Милана), Transport and Traffic Engineering Faculty, Belgrade, 2002 (in Serbian).

5. Stanic, B. et al: King Milan Street Zone - The Results of Traffic Counting (Бројање саобраћаја у зони Улице краља Милана), Transport and Traffic Engineering Faculty, Belgrade, 2002 (in Serbian). 